\title{
THE SHEN MODEL FOR MAKE-TO-ORDER SME'S
}

\author{
SHALADDIN MUDA \\ ZULKIFLI MOKHTAR \\ SEMANAT ABU BAKAR \\ Faculty of Management and Economics \\ Universiti Malaysia Terengganu
}

\begin{abstract}
This paper describes a new model developed for make-to-order (MTO) sectors namely SHEN Principles, which aims to fill a gap in the world-class manufacturing (WCM) literature that concentrates on the characteristics of the larger traditional make-to-stock (MTS) sector. Using evidence from the

literature, especially the MTO literature and the more comprehensive WCM models, a new model was devised. This was then modified in the light of case study evidence collected from the six MTO companies ranging from small-to medium-sized MTO companies. The model presented in this paper known as "SHEN Principle", will be the current version of the model after all the modifications have been incorporated.
\end{abstract}

Keywords: SHEN principle, make-to-order, world class.

\section{- Abstrak}

Kertas ini menerangkan pembentukan model baru bagi sektor buat-untuk-tempahan (MTO) yang dinamakan Prinsip SHEN, yang bertujuan untuk mengisi ruang dalam sorotan karya pembuatan bertaraf dunia (WCM) yang memfokus kepada ciri-ciri tradisional dalam sektor buat-untuk-stok (MTS). Berdasarkan bukti-bukti dari sorotan karya, terutamanya sorotan karya MTO dan WCM yang lebih komprehensif, sebuah model baru telah dibangunkan. Ia kemudiannya dimurnikan berdasarkan kepada bukti daripada kajian kes yang dijalankan di enam buah syarikat MTO bersaiz kecil hingga - sederhana. Model ini dinamakan Prinsip SHEN, merupakan versi terkini selepas pemurnian dibuat.

Kata kunci: Prinsip SHEN, buat-untuk-tempahan, taraf dunia.

\section{Introduction}

Much of the literature on 'world-class manufacturing' (WCM) has concentrated on the 'make-to-stock' (MTS) sector (Muda \& Hendry, 2002; 2003). Little attention is given on how to apply world-class concepts in the "make-toorder' (MTO) sector. This laxity may be due to the assumption that this sector can be treated in the same way as the 'make-to-stock' (MTS) sector. However, 'make-to-order' companies operate differently from 'make-to-stock'. The business is based on producing a special kind of product to customer specifications rather than producing standardised parts to stock. The production only starts when the customer places an order. To win an order, the company has to compete with other companies on the basis of price and the 
delivery date. On the other hand, make-to-stock companies produce and place their products in inventory before receiving a customer order. The customer may purchase the product directly from an inventory at a retail outlet or at the factory distribution centre.

The aim of this paper is to fill the gap in the literature by developing a comprehensive performance-improvement principle for the MTO SME sector. The new principle, which has been named the "SHEN principle", is therefore contingent on company type. This paper describes the current version of the principle and the research process followed to develop it (refer to Muda et al., 2003; Muda et al., 2002). This included deductive research whereby the initial principle was developed using literature evidence and the past experience of the authors, followed by inductive research in which case study data was collected from six MTO SMEs in the Northwest of England in order to develop the principle further. The principle aims to help companies determine which performance improvements are needed and how to prioritise them in the race to be world class.

The case study research was exploratory in nature and aimed to gain further insights into the issues and solutions that were pertinent to MTO SMEs. This was achieved by first looking at the current operations performance and practices in each of the companies, and exploring with personnel any projects that had been undertaken but had not led

" to satisfactory implementations. By comparing this data with the initial SHEN principle, areas of strength and areas of weakness were postulated along with a list of potential improvements. These findings were then discussed with the company management to determine whether they agreed with the assessment of the company and the ideas on how MTO companies should seek to remain competitive in the future. The results suggested that some of our initial assumptions needed to be modified. For example, it was initially assumed that MTO companies should aim for a high level of worker flexibility, higher even than was achieved in the MTS sector, given the high variety of customized products. However, it was concluded that training is expensive in this highly skilled sector and that it is often only necessary to have a few workers trained for particular processes. Therefore, a training-need matrix should be devised which establishes the number of people that need to be trained in each skill. Any further training is unnecessary and will soon be wasted as, without the experience of using the new skill, it is likely to be quickly forgotten. Thus the current version of the SHEN principle presented here incorporates changes to some of the assumptions in the light of the case study evidence.

\section{Make-to-Order Concern}

The model was based on several ideas from the general literature on MTO firms and the WCM literature that concentrates on the characteristics of the larger traditional make-to-stock (MTS) sector. It is the assumptions made in these models, such as the degree of variety and the volumes being produced, that suggest that they will be more applicable to MTS. Aspects of the models that rely on the assumptions of high volumes and low variety need to be removed to make the models relevant to the MTO sector that tends to produce in smaller volumes and with a higher degree of variety. The MTS operation remains distinct from the MTO as the products in the MTS companies are designed by the company prior to receiving the customer's orders. They are mostly standard products that can be produced in large quantities and stocked if it is economical to do so.

In some cases, products can be modified according to customer requirement, and therefore are not produced until an order is placed, but nonetheless there is a large degree of similarity between products. In contrast, the MTO company manufactures products to customer specification. Hence production cannot commence until an order is confirmed and there is little scope for holding stocks or benefiting from efficiency gains that are associated with repeat production. 


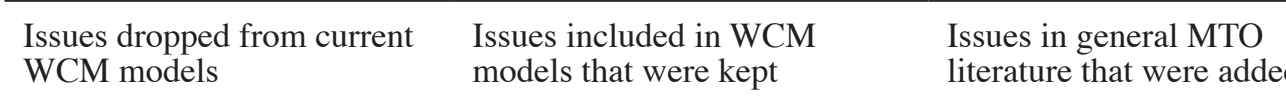

- Product families - MTO company does not have a product line.

- Regular customers Some MTO companies need to compete every time they received customer enquiry.

Repeat production - Most MTO producing different kinds of product based on different kinds of specification and design.

- Limited number of suppliers - Many different components.

- A cellular or other simplified layout - MTO company does not have product line.

- Zero defect or related.

- A team that focuses on a specific product or customer families.

- Operate close to customers' rate of use or demand - This idea is dropped because MTO actually describes this type of firm.

MTO firms only produce items that have been ordered.
- Simplify the shop floor, includes housekeeping, movement of raw materials and storage system.

- Simple, flexible, movable, low cost equipment in multiples.

- Cut the flow time.

- Cut the changeover/ set up time.

- Preventive maintenance.

- Improve information flow.

- Computerised office transaction.

- Appreciation to workers.

- Rewards and recognition.

- Company investing in training.

- Strategic or operational planning.

- Sharing information and records with employees.

- Employees' suggestions.

- Quality, speed, flexible and value.

- Continuous improvement.

- Customer complaints and satisfaction data

- Benchmarking

- Quality accreditation

- Advertisement
- Marketing and production functions integration - Problems caused by different objectives. [Kingsman et al. (1993), Lee and Kim (1993) and Hendry et al. (1993), Hendry and Kingsman, (1989)].

- The nature of design process- able to produce different kinds of product based on different specifications and drawings. [Amaro (1997), Jina et al. (1996)].

- The nature of any "repeat" business which can be obtained and the consequent relationship. Some MTO businesses known as RBC have the ability to achieve the repeat business. [Amaro et al. (1999)].

- Flexibility of process that often requires a job shop layout - not a cellular or group technology. [Hendry (1998), Jina et al. (1996), Ward (1994), Ferras, (1994)].

- Methods of job shop control; workloads/queues. [Melynk \& Ragatz (1989);

Philipoom et al. (1993); Lingayat et al. (1995), Bergamaschi et al. (19960, Land \& Gaalman (1996, 1998), Zapfel \& Missbauer. (1993)].

- Pride of craftmanship Highly skilled workers is a strength of the MTO. [Hendry (1998)].

- Collaboration with customers - Company helping the customer to define the needs into product specification and design. [Amaro et al. (1999), Hendry, (1998)]. 


\section{SHEN Principle}

The SHEN principle contains 12 propositions, each comprising five steps. Level one is the first step on the road to improvement and level five relates to the current best-practice performance. In order to use the principle, it is intended that companies will assess their current practices and performances to determine which levels of achievement they have attained for each principle. This should lead to a set of company strengths and a set of potential company improvements. The management will then need to consider the latter carefully to determine how to implement them in its particular manufacturing environment.

\section{Table 1}

The SHEN Principle

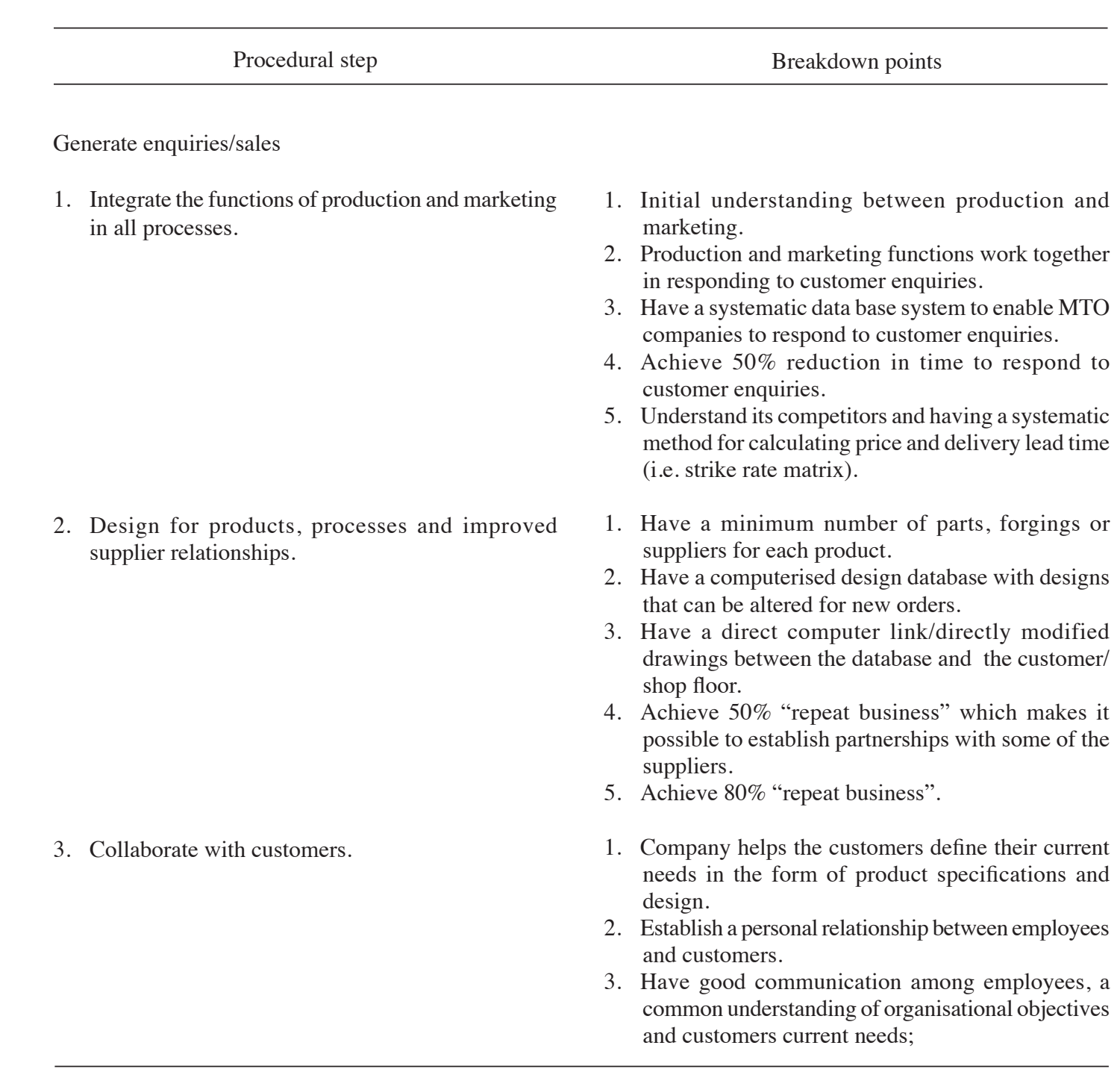


Operations and capacity

4. Simplify the shop floor.

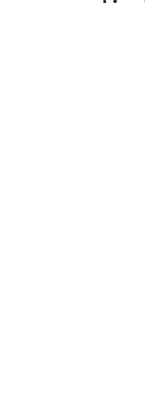

5. Improve scheduling and workload control to cut flow times;

6. Cut the start up/changeover time and improve preventive maintenance;

7. Improve information flow;
4. Get customer representatives on the project;

5. Help the customers meet their goals, rather than provide customers' wants.

1. Improve visibility, use simple storage systems to reduce search times.

2. Train shop floor employees on the importance of using the storage systems and of taking responsibility for their own housekeeping.

3. Implement housekeeping so that work areas are clean as well as ensuring that the storage systems are properly used.

4. Improve locations of raw materials, WIP etc. to cut distances for movement of materials and tools.

5. The operator takes over his own housekeeping.

1. Have a practical, simple and easily implemented manual scheduling system.

2. Have a simple computerized scheduling system which can be modified as priorities change.

3. Have an effective method of workload control to aid the company to reduce flow times.

4. Achieve average reduction of flow time by $30 \%$.

5. Achieve average reduction of flow time by $50 \%$.

1. Train associates in set-up/ changeover reduction and basic preventive maintenance.

2. Achieve $10 \%$ average reduction in set-up/ changeover time.

3. Operators can take over their own preventive maintenance.

4. Achieve $20 \%$ average reduction in set-up/ changeover time.

5. Employees achieve $30 \%$ reduction in set-up/ changeover times across all processes.

1. Job priorities are clearly understood by all and everyone is working to the same plan.

2. Have a systematic method to communicate the plan including manual systems such as a planning board or 'work-to' lists produced by an appropriate software package.

3. Office transactions, labour transactions cut by $25 \%$.

4. Internal transactions cut by $50 \%$ and $80 \%$ of external transactions are done by fax/Internet/EDI.

5. Internal transactions cut by $80 \%$ and $99 \%$ of external transactions are done by fax/Internet/EDI. 
Human resources

8. Make essential improvements in skills and flexibility;
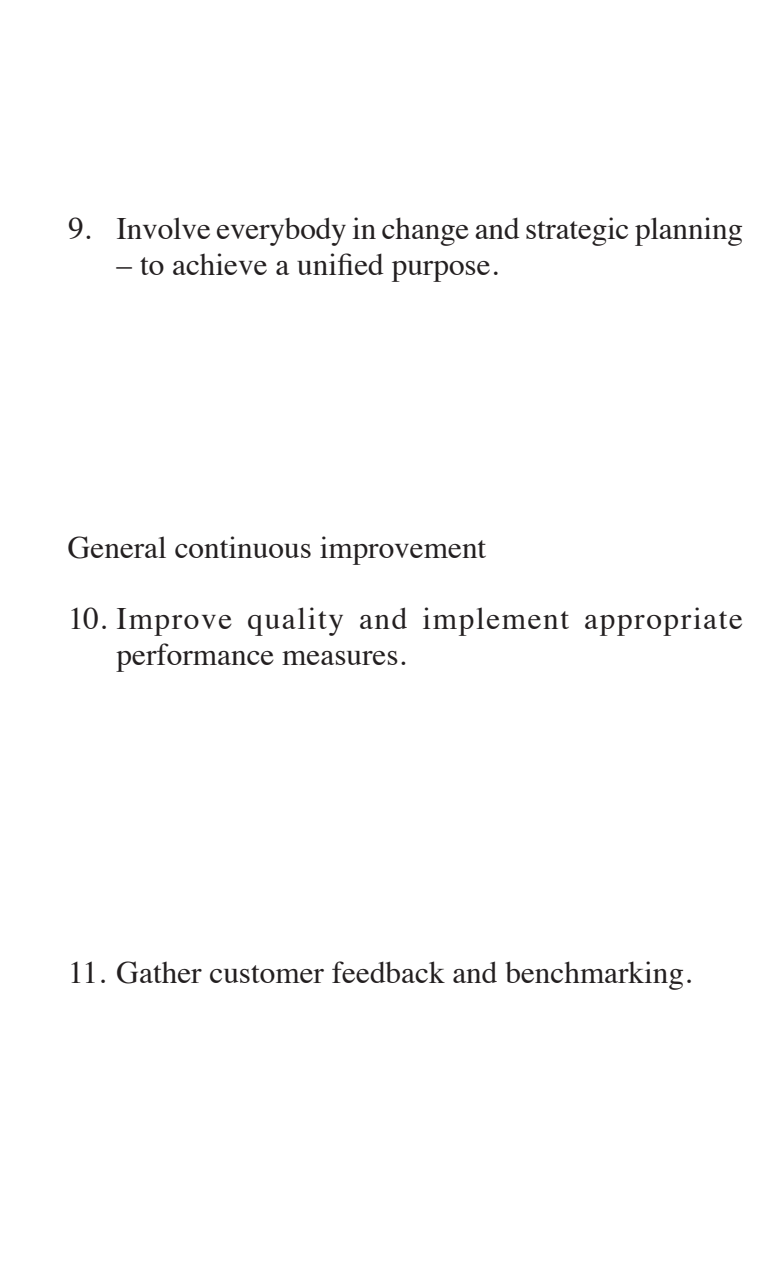

12. Promote/market/sell every improvement.
1. Implement a training programme for all associates to increase relevant skills.

2. $80 \%$ of associates are flexible in appropriate skills and able to work on other machines when needed.

3. $99 \%$ of associates are flexible in appropriate skills and are able to work on other machines when needed.

4. Experts teach operators to do repairs; downtime cut by $50 \%$.

5. Operators become technicians; downtime cut by $80 \%$.

1. Encourage employees to make suggestions to improve the process.

2. Have strategic planning.

3. Share information and records with shop floor employees.

4. Systematic public recognition/celebration of achievement.

5. Variety of low-cost awards to both teams and individuals.

1. Practice the principles of quality.

2. Understand (through training if necessary) universal customer wants: quality, speed, flexibility or value (QSFV).

3. QSFV are dominant performance measures.

4. Second order performance measures (e.g. labour productivity, variance) no longer managed.

5. Maintain a culture that supports continuous improvement in all processes.

1. Gather customer-satisfaction data, review complaints and make continuous improvement on products and services.

2. Gather data on future customer needs.

3. Gather competitive samples and best practice data.

4. Involve all associates in customer/competitive best practice.

5. Implement full-scale benchmarking for the company's processes.

1. Have good advertisements with effective placing (newspaper, magazine, etc.) for the target customers.

2. Feature positive QSFV trends in selling, bids, proposals, ads.

3. Registration; certifications; local awards (ISO-9000, Ford Q1, state award).

4. Other local/national/global awards.

5. Reverse marketing: Out of strength, you choose whom you sell to. 


\section{The Five-Step Improvement Scale}

The SHEN principle as shown Table 1 groups its principles into four categories, each containing several inter-related principles. The categories are intended to assist the company to track achievement based on related activity. In some cases, the grouping may also help the company to decide how to prioritise the changes needed in its improvement programme. The main objectives of the first category, "generate enquiries/sales", are (a) to provide a quick response to customer enquiries, (b) to translate customer enquiries into product specification and design, and (c) to make the necessary plans to ensure that operations can meet the customer's goals. Under the second category, "operations and capacity", the shop floor operation is organised to help ensure a steady flow of materials. Activities include determining lead-time, set-up time, preventive maintenance, housekeeping and scheduling. The next category, "human resources", refers to the improvement of the company's workforce and finally the fourth category of the SHEN principle, "general continuous improvement", covers the aspects of quality and performance measures, benchmarking and marketing.

It is important to note here that the five steps are not intended to be used as part of a scoring system, as has been the case in previous models such as Schonberger (1996). Indeed, it could be argued that scoring companies is not possible using any WCM concept as they are not precise enough to be used for such judgmental purposes. Rating or scoring is only possible if the numbers of the steps represent equal increments of the attribute being measured (e.g. the Likert, Thurstone scale). In such a case, the differences can be compared; for example the difference between 1 and 2 is the same as that between 2 and 3. This makes it possible to compute an arithmetic mean from the scores and the data is referred to as an "interval scale". However in the SHEN principle, it is not possible to distinguish the exact value/ amount of difference between the steps in each principle. Aaker et al. (1995) describe scales of this type as "ordinal" rankings. According to The New Webster Encyclopedic
Dictionary of the English Language (1997), an ordinal ranking refers to any numbers that express degree, quality or position in a series, as first, second and third etc. Aaker, Kumar and Day (1995) claimed that "ordinal" rankings provide information on the differences between the improvement activities but without indicating the exact amount of difference. Therefore it is not possible to compute a mean ranking in ordinal scales because the differences between the ordinal-scaled values are not necessarily the same (Aaker et al., 1995). For example being in level 4 in one principle doesn't mean being twice as good as level 2 .

\section{Detailed Explanation of The Shen}

This section discusses each of the principles in greater depth. The main aim of this section is to identify what is appropriate to achieve at each of the five "levels of attainment" for each principle.

\section{Principle 1: Integrate the functions of production and marketing in all processes}

In a MTO company, it is necessary for the production planning and marketing departments to work together to determine the bidding price and the delivery date to be quoted for each job. At the one-point level, there should be at least a general understanding between the production and the marketing sections to achieve common company goals. This means that instead of production looking to reduce costs and marketing looking to maximise sales, there is an understanding that it is overall profits that are the most important objective. At the second level these two sections are required to work together during the customer-enquiry stage so that customer demands are agreed to be realistic by production, as well as competitive by marketing. A deficiency of co-ordination between marketing/sales and production at the customer-enquiry stage can lead to confirmed orders being delivered later than promised and/ or being produced at a loss. As indicated in Figure 1, this lack of co-ordination has typically meant that the marketing department alone deals 
with the customer-enquiry stage, maybe with some interaction with engineering. Then the accepted job is handed over to the shop floor at the job release stage and it is only then that production considers the implications of the job on shop floor capacity and the current planned schedules. If production is involved earlier, then the effects of new orders can be anticipated sooner and any necessary changes in capacity can be provisionally planned in advance. At the fourth level, a $50 \%$ reduction in estimation time to respond to customer enquiries is required. The target of $50 \%$ was thought to be realistic once the database is properly in place and is desirable from a customer's perspective that the time to respond to customer enquiries cannot be too long (Henderson, (2001)). However consideration has to be given to the accuracy of the cost estimates produced.

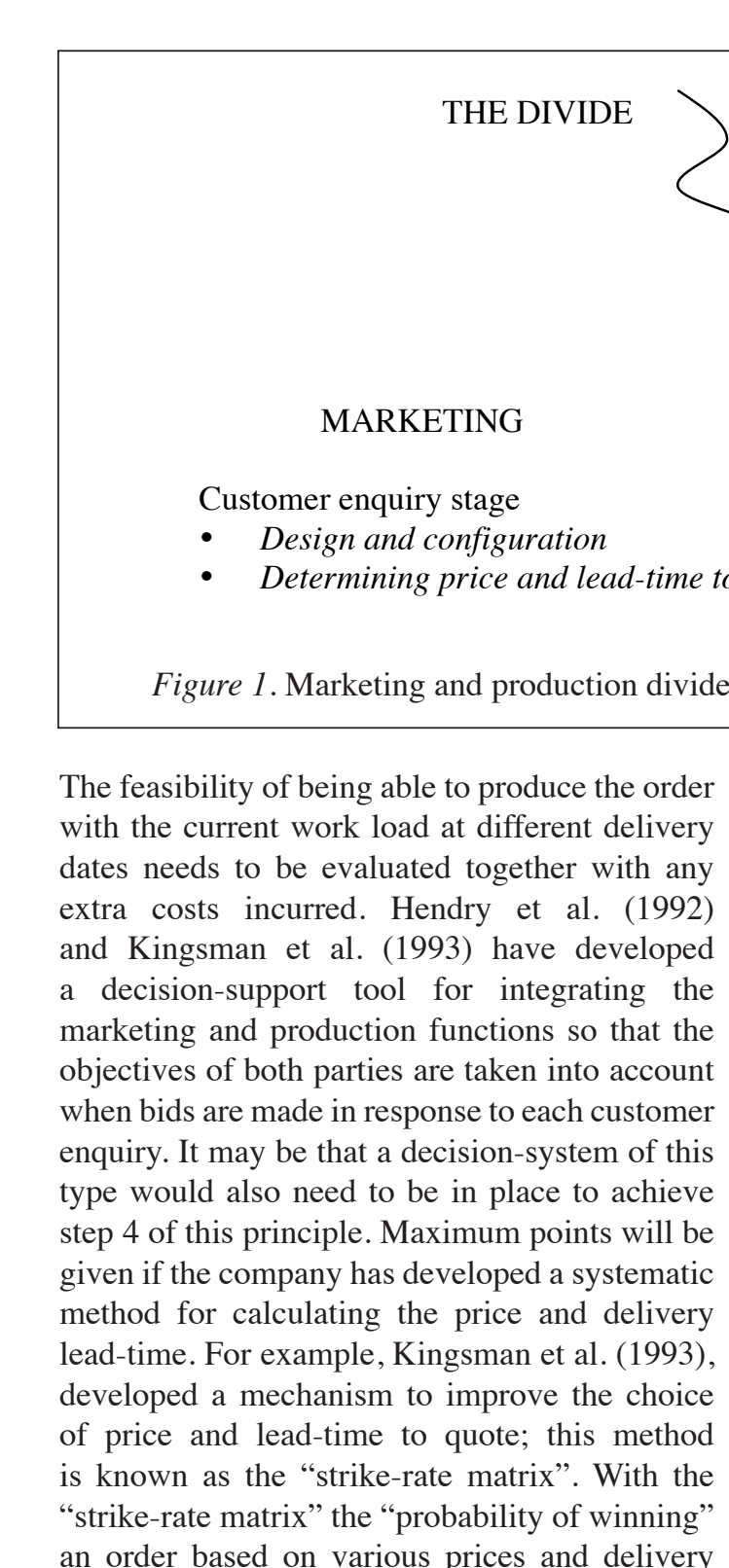

\section{PRODUCTION}

Job release stage

- Production planning at releasing tol loading of shop floor.

- Scheduling through work centres and individual machines.

Customer enquiry stage

- Design and configuration

- Determining price and lead-time to quote

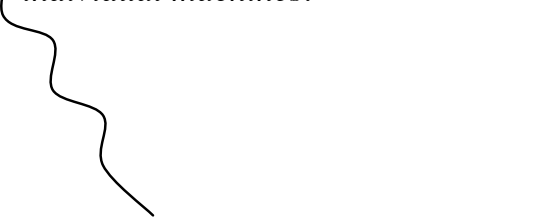

Figure 1. Marketing and production divides (adapted from Kingsman et al., 1993).

The feasibility of being able to produce the order with the current work load at different delivery dates needs to be evaluated together with any extra costs incurred. Hendry et al. (1992) and Kingsman et al. (1993) have developed a decision-support tool for integrating the marketing and production functions so that the objectives of both parties are taken into account when bids are made in response to each customer enquiry. It may be that a decision-system of this type would also need to be in place to achieve step 4 of this principle. Maximum points will be given if the company has developed a systematic method for calculating the price and delivery lead-time. For example, Kingsman et al. (1993), developed a mechanism to improve the choice of price and lead-time to quote; this method is known as the "strike-rate matrix". With the an order based on various prices and delivery dates can be determined. In brief, it is necessary to gather data on bids that have been tendered in the past including those lost and those won. For those lost, this means collecting data about the company's competitors, either indirectly by ringing the customers to compare the price tendered by its competitors or by contacting the competitors direct.

\section{Principle 2: Design for products, processes and improved supplier relationships}

Principle 2 is to cut out wasteful practices in product design and delivery. Advice within this category includes the need to have a good understanding of the design so that quality tolerance can be brought close to the target value or specification. Improving the design is very important to make the product easier to manufacture with less error. Once this is done, 
production becomes smoother and manufacturing can then proceed more easily with less need for inspection and test, which add no value.

At the one-point level, the shop floor should be a source of ideas and the machine operators should be trained to understand the product design process. Having a computerised-design database which can be modified for new orders in the second-point level can give a lot of advantages to MTO. It can reduce the time for product design which in turn can shorten the response time to customer enquiries. Where possible, some basic designs may be stored in a computer and modifications based on a customer's needs could be made for each new order. Even if no basic design exists, it may still be possible to modify old orders rather than starting from scratch each time.

-

At the third level, the company has successfully reduced the number of suppliers for its product. The idea of reducing the number of suppliers in MTO may be achieved through the commonality of parts or 'forging'. However, any improvement in company performance resulting from changes in this area will be much smaller than those - expected and achieved by the producer of more standard products (Hendry, 1998; Heizer et al., 2006). Therefore no percentage figure is given, but the company must have addressed this issue and be confident that parts, forgings and suppliers have been reduced as much as possible.

In terms of "repeated business" referred to in steps 4 and 5, the MTO firm may establish a longterm continuing repeat business with a specific customer and for a product specifically produced for that particular customer. One of the aims for repeat business is to make the business secure with guaranteed jobs for a reasonable period into the future. A firm which has achieved repeated business could shift toward good partnerships with its suppliers. With partnership, the MTO companies may stay with few suppliers and enable the learning curve to work for the benefit of both parties. Some contracts in a "repeat business" specify the quantity of purchasing for the next few months and provide the forecast for the rest of the year, whilst other contracts may not stipulate the exact quantity. However in both cases, these contracts can reduce the manufacturing cost and thus reduce the costs to the customer which is important to gain a competitive advantage in the MTO businesses. .

\section{Principle 3: Collaborate with customers}

The first level of this principle requires a common shared understanding of the company business among the employees, with particular reference to customer needs. Issues of this type are applicable to all SMEs. In fact, the smallness of the company makes the task of communication easier to achieve.

At the two-point level, the MTO company can make effective use of a good relationship with its customers to ensure complete satisfaction on current jobs and to gain more jobs in the future. To this end, the company may assign one particular individual to have constant contact with one particular customer. That individual will be responsible to deal with any kind of requirements needed for that particular job. Customer requirements may change during any stage of the project. This person must be very clear on the customer requirements because one of his/ her jobs is to transform requirements into service specifications. Getting customers' involvement on a current project at the third level is the next improvement for the MTO company to aim for. For example, the two parties may work together to ensure appropriate standards of quality are attained. The highest level will be achieved if the MTO company helps its customers to meet even more general goals, rather than provide what the customer knows he/she wants. For instance, the company may help the customer to design a new module or product that is beyond the customer's expertise.

\section{Principle 4: Simplify the shop floor}

Under this principle, improving visibility, having efficient storage systems, and efficient housekeeping are the main contributing factors. The one-point level requires the company to 
improve the shop floor visibility to make the movement of raw materials and tools easier. One of the important tasks for the shop floor manager is to reduce the time for searching for materials and components. Time is sometimes squandered searching for components or worse, making parts that are in fact already available. The second-point level requires the firms to improve their storage systems further so that they can be deemed more efficient. For instance, putting the raw materials near the area in which they will first be used wherever possible can eliminate the need for a warehouse of components. At the three-point level, the firm is required to provide training to its workers on the importance of using the storage systems and of taking responsibility

for their own housekeeping. At the fourth level the firm is required to discipline its workers to do the housekeeping job. The concept of " $5 \mathrm{~S}$ " housekeeping comes from the Japanese words "Seiri, Seiton, Seisou, Seiketsu, Shitsuke" which means liquidation, tidiness, sweeping, cleanliness and discipline (Morton, 1994). According to Schonberger (1996), Boeing's version of " $5 \mathrm{~S}$ " means sorting, sweeping, simplifying, standardising, and self-discipline. Everything is marked or labelled. All items such as brooms, mops, and other cleaning materials are neatly placed in designated places when not in use. Display boards are used to describe the 5 S's and show photos of proper and improper housekeeping in the company. At this level, the management may need to keep reminding its employees to tidy up their own areas, but nonetheless improved housekeeping should result. The five-point level requires the shop floor operators to take over their own housekeeping. Under this concept, the employees maintain their own equipment without supervision and keep everything in a benevolent order.

\section{Principle 5: Improve scheduling and workload control to cut flow times}

Methods of controlling the workloads or queues to better control flow times, and hence manufacturing lead times, in the MTO sector have been discussed by authors such as Muda et al. (2002,2003); Hendry (1998). They include an approach called Workload Control (WLC) or Order Review and Release (ORR); finite/infinite scheduling along with dispatching rules or just improving the storage systems and housekeeping as discussed in principle 4. Whatever the method, the issue of reducing lead times is very significant for the MTO companies because they are frequently in a position of having to quote lead times to their customers before production begins and therefore the length of the manufacturing lead time is visible to the customer. At the firstpoint level, everybody on the shop floor must be trained to understand the job-shop sequencing, queuing limitation, workload control and handling priority. Last minute production control decisions are often made by shop floor workers and therefore the principles of production-control should be understood by all relevant personnel, not just stored in the head of one employee, the Production Controller. At the two-point level, the MTO production control system does not need to be computerised. In fact the MTO company can make effective use of manual production control boards to display "work-to-lists" or to schedule the jobs. However there should be some form of scheduling or workload control system in place which should reflect job priorities in its sequencing decisions. The third level requires the MTO company to use computer software in its production- control system. However, to implement a workload control system of this type would require the implementation of computer software that is not yet readily available on the software market and hence 'inhouse' systems would need to be developed by using simple computer packages (e.g. EXCEL). Alternatively, it may be possible to consider the use of software that is readily available, such as finite capacity planning techniques which load the planned jobs onto the machines according to the available capacity constraints. The fourth and fifth levels of improvement suggest that the company should achieve some improvement in its flow time. As long as the MTO firm can achieve these objectives, it does not matter what type of scheduling or workload control method is used. 


\section{Principle 6: Cut the start up/changeover time and improve preventive maintenance}

Another aspect of non-value-added time is machine-down time. If preventive maintenance can reduce this, then flow times can be reduced further. Similarly, reductions in setup/changeover time will also lead to shorter manufacturing lead times. Cutting set-up time also permits the shop floor to increase the plant capacity by making the machine available for use for longer periods. There are many ways of reducing set-ups. For example, ensuring tools are stored in a convenient place can save a lot of time. Changing fittings so that they are slotin rather than screw in and ensuring that there is adequate manpower to operate machines when a change of set-up is needed can also save a lot of time. The third level requires the machinists to take over their own preventive maintenance. Preventive maintenance requires that equipment must be maintained to meet the required process. Operators can do simple things like adding lubricant, checking for wear, listening for unusual vibration or repairing minor problems. In addition, the tools, and barrels of lubricants can be placed near the machines in exact locations for easy grasp. Having appropriate maintenance policies will enable the shop floor to maximise the usage of the machines. The higher levels, 4 and 5 , require the company to search for ways to reduce its set-up time further by $30 \%$ at level 4 , and then by $50 \%$ at level 5 , across all processes.

\section{Principle 7: Improve information flow}

The two main issues that underlie this principle are to eliminate workflow transactions and to simplify the communication process internally and externally. The first level requires that job priorities are clearly understood by the employees and that everyone in the shop floor is working to the same plan. It may be a rough, or unwritten schedule but it must at least be understood by all employees. The second level requires the company to have a systematic control system to cut internal transactions. Conceivable techniques include manual systems such as a planning board or 'work-to-lists' produced by an appropriate software package. If the latter, information may be available via the computer terminal, thus reducing internal paper transactions. The third level requires that employees should be clear about the targets (i.e. on quality, cost, orders, delivery, design) and standards of performance required, whatever those may be. They should be able to track all kinds of information on the shop floor. Advice for four to five levels includes the need to cut internal and external transactions. Examples of internal transactions are the use of "manual" tracking records to register the arrival of raw materials/components and the dispatch of finished goods, which are considered as "time-wasters" for managers. Such practice leads to an increase in internal transactions. An alternative solution is to automate the process. Hendry et al. (1995) suggests that a bar-coding system is a faster method of data collection than the manual. With a bar-coding system, the company can improve the recording of stock movements and the receipt of products against work orders (Hendry et al., 1995). Regarding external transactions, the MTO firm can achieve reductions through the usage of electronic data interchange, fax machines and computer links. Information on delivery, ordering of parts, designing and so on can now be exchanged very quickly between all the parties involved in the process.

Computer networks are beginning to play an important role in the successful operations of small businesses (Baar, 2000). Many online services can be used by the MTO firm to improve the process such as electronic mail (e-mail), sharing of documents, proposals, files, marketing catalogues, order processing, networking, and business and market research. E-mail for example, can be a quick economical way to communicate worldwide. This is very good scheme for small companies that do not have access to a large budget.

\section{Principle 8: Make essential improvements in skills and flexibility}

Due to the nature of the MTO processes, the employment of well-trained and highly skilled 
employees is essential if the company is to provide the levels of product flexibility and customisation required. The second and third levels require the MTO company to reach a point whereby first $80 \%$ and then $99 \%$ of the workers have the flexibility to work on any machine. These high levels are deemed feasible because a high skill base and a high degree of flexibility are inherent characteristics of the MTO firm. At the fourth level, training and instructing colleagues may become part of everyone's regular job, especially those that have achieved a level of expertise in an aspect of the operation processes. These experts may be internal or external people but internal is preferable because both the trainer and the trainee can communicate several times even after the training session.

\section{Principle 9: Involve everybody in change} and strategic planning - to achieve a unified purpose

Most MTO companies have people categorised as "front-line employees", "bosses", or "staff experts" who are inspirational leaders. The employees gather and analyse their own process data and thus have the power of process knowledge. Bosses, experts and employees work together and share the knowledge to improve the process. Level 2 requires a MTO company to have a strategic plan. Strategic planning consists of an overall plan to effectively guide the company as a whole. Good examples of planning will specify the company's strategic objectives (e.g. high quality products, low costs, short time to market) and give some indication of the methods for attaining them. For level 3 , the company needs to inform its workers about its strategic plan and share the relevant data (e.g. whether aims are being met) with its shop floor employees. This process data may include data on reductions in defects and non-conformities, flow times, set up times, housekeeping activities and so on. Some information related to quality processes such as scrap reduction and defect prevention may be used by functional teams, but other things like delivery-date adherence may need to be done at the supervisory level. However, any done at the supervisory level must be displayed on the shop floor at appropriate locations.

\section{Principle 10: Improve quality and implement appropriate performance measures}

Quality applies to goods, services and processes. A good quality product has a minimum variation around the specified values, or is well within the quality tolerances. When the processes are improved the goods and services improve too. Quality requires a continual and rapid improvement in all processes. The idea is to find ways of preventing problems occurring in the process so that outputs of the process are always good.

The first level requires the firm to establish a culture that supports continuous improvement in its processes. Usually, before any improvement can be made, the management needs to develop this type of culture, so that any new concept is welcomed and explored rather than be automatically criticised and thrown out. At the second level the quality practices may not be visible on the shop floor but the management is very particular about the quality in its processes. The second-point level requires the company to provide training in universal customer wants (QSFV). The MTO firm may have some prioritisation between these four objectives, and may even have other objectives that are more suitable. The key issue at this level is to train employees in the relative importance of the company objectives.

At the fourth-point level in this principle the company objectives, which may include improvements in QSFV, become the dominant performance measures. At the fifth level, it is necessary to get rid of "second order" performance measures. The reason is that "second order" performance measures are irrelevant to the company's real business objectives. Presenting such data to the workforce every month will give negative signals. "We cut nonconformity, cut setup times, cut the flow time, did the preventive maintenance, and what did it get us? Higher unit costs on the monthly cost report!" (Schonberger, 
1996). Of course, investment in these activities requires additional costs but it should not be part of the company's assessment or measurement. Presentation of such data to the shop floor could be made later, maybe during an annual meeting when it is also possible to see that the investment has paid off and has led to improved company performance.

\section{Principle 11: Gather customer feedback and benchmarking}

Customer feedback and benchmarking can be -used as a tool to gather information that may lead to the increased success of a company. At the first level, systems are put in place to collect customer feedback and to review the customers' complaints. The former may include questionnaires sent with the product on delivery or may mean telephoning customers on receipt of products. This data must be regularly reviewed, analysed and acted upon. Where there are complaints, it is necessary to take immediate action to 'fail-safe' the problems. Customerneeds data at the second level means attempting to find out what the customers will require m in the future. Similarly, at the third level, the competitive samples and the best-practice data can be used as a source of information for the company to improve its operations and be more competitive in the future. Competitive samples may include collecting samples of competitors' products. Clearly, this strategy requires identifying the products and services offered by competitors and how to make the company superior to its competitors. Best practice refers to additional data, which go beyond the product, for instance, filing systems, payroll systems and so on.

The fourth level requires the involvement of all employees and not only the managers to help the company strengthen its competitive status. This means that all employees may be involved in collecting competitive samples or customerneeds data to search for better ways to operate the company. Finally the fifth level requires the company's effort to go for a full scale 'benchmarking' in its operations. According to Beasley and Cook (1995), the five main reasons for a company's benchmarking are "to change or strengthen the company culture; to increase the company's competitive advantage; to create awareness; to enhance operational awareness; to enhance operational performance; and to manage the company strategically".

\section{Principle 12: Promote/market/sell every improvement}

Promotion is a mix of activities that includes advertising, publicity, direct mail, telephone calls and sales presentation. Planning for promotional campaigns involves choosing appropriate advertising media, the audience, and the effectiveness of the message/campaign. At the first level, the MTO promotional campaign may be made through trade exhibitions, trade journals, telephone calls, direct mail, internet web pages or the yellow pages of the phone book. For example, the Internet (web pages) is considered as one of the best places to advertise because it is fast and easy to access by the customers. The second level requires the special MTO features, which may include some of the QSFV or other performance measures, to be publicised. However, the third level requires a lot of company effort to gain international recognition such as state awards or ISO 9000 awards. The intention of having ISO 9000 recognition is to provide confidence to customers that the intended quality is being achieved and sustained. Nowadays, companies that do not conform to the ISO 9000 standards are likely to find that they will not be able to sell into certain markets, thereby reducing their sales potential (Shores, 1994). The fourth level requires the MTO firms to go beyond ISO 9000 or state awards to aim for national or global awards. The fifth level of achievement for this principle is where the company can price itself out of the market, if it wants to. If the company can build these practices, it is at a great advantage. The company can pick and choose the customers rather than the company itself searching for customers. 


\section{Conclusion}

The new principle, "SHEN", groups its principles into four categories, each containing several inter-related principles. The category titles are generate enquiries/sales, operations and capacity, human resources and general continuous improvement. Each category comprises of three principles with the exception of operations and capacity, which has five. The first few principles from the lists 1, 2, 3, 4 and 6 contain most of the material relating to the MTO companies that tends to be missing from previous WCM models in the literature. These include the integration of the functions of production and marketing, the product-design process, customers' relationships and so on. The remainder of the principles are built/modified from generic, universalistic literature that is aimed at all manufacturing companies. The latter include issues on performance measurement, benchmarking, housekeeping, preventive maintenance, human resources and so on. However, even where this type of material is present, the principles have been carefully tailored to suit the high variety, low volume MTO environment.

-

\section{Areas for further research}

The following issues represent potentially interesting continuations to the present study:

- At the moment the 12 points of the SHEN principle are not given in any particular priority order. Instead the principle just identifies the set of issues. This is because it was felt that before a priority ranking could be found it is important to make sure that the list of possible improvements is comprehensive. Further research is needed to enable companies to determine which changes to make first and whether to make changes simultaneously or sequentially.

- It is essential that the principle should be useable by companies without the need for expert interpretation. Thus, future research will also involve the investigation of alternative methods of principle presentation, including the possibility of using a workbook that can be used by company personnel to devise their own improvement programmes. In particular, such a workbook should provide some type of cost/benefit analysis so that companies can prioritise the various improvement options and allocate their limited resources to the best effect.

- The ideas developed so far have been addressed to SME MTOs. Further research is needed in order to examine the applicability of the approach to the larger-sized MTO firms. If the approach is to be implemented in these companies, investigations are required to establish whether a new model would be essential, or whether the existing SHEN model would meet the needs of the larger-sized MTO firms.

\section{References}

Aaker, D. A., Kumar, V., \& Day, G. S. (1995). Marketing research. New York: John Wiley \& Sons.

Baar, A. (2000). Startup targets small business. Adweek. Midwest Edition, 41(51), 5.

Beasley, G., \& Cook, J. (1995). The 'what,' 'why' and 'how' of benchmarking. Agency Sales, 25(6), 52-55.

Clifford, J.P.(1999). The collective wisdom of the workforce: Conversations with employees regarding performance evaluation. Public Personnel Management, 28, 119-56.

Deshpande, S.P., \& Damodar,Y.G.(1994).HRM practices in large and small manufacturing firms: A comparative study. Journal of Small Business Management, April, 4956.

Garsombke, T. W., \& Garsombke, D. J. (1989). Strategic implications facing small manufacturers: The linkage between robotisation computerization, automation and performance. Journal of Small Business Management, 27(4), 34-44.

Grieco, Peter L., Jr. (1996). World class customer. Executive Excellence, 13( 2), 10-11.

Heizer, J., \& Render, B, (2006). Operations management (8th ed.). New Jersey: Pearson Prentice Hall. 
Henderson, I. (2001). Why is making-to-order so different? BPIC Control, December/ January, 19-23.

Hendry, L. C. (1998). Applying world class manufacturing to make-to-order companies: Problems and solutions. International Journal of Operations and Production Management, 18(11), 1086-100.

Hendry, L. C., Wilson E., Kingsman B. G., Worden L., \& Mercer A. (1992). Dynamic planning of resources for make-toorder companies. Proceedings of the Eighth International Conference on Computer Aided Production Engineering, Edinburgh, 159-65.

Kingsman, B. G., Worden, L., Hendry, L. C., Mercer, A., \& Wilson, E. (1993). Integrating production planning in maketo-order companies. Proceedings of International Conference on Managing Integrated Manufacturing, 1, 427-36.

Liberatore, M. J., \& Titus, G. J. (1996). The use of computer controlled tools by small machine shops. Journal of Small Business Management, 24(1), 55-62.
Shaladdin, Muda., \& Hendry, L. C. (2002). Developing a new world class model for small and medium sized make-to-order companies. International Journal of Production Economics, 78(3), 295-310.

Shaladdin, Muda., \& Hendry, L. C. (2003). The SHEN model for MTO SME's: A performance improvement tool. International Journal of Operations and Production Management, 23(5), 470-486.

Morton, C. (1994). Becoming world class. UK: Macmillan Press.

Russel, R. S., \& Taylor, B.W. (2006). Operations management (5th ed.). USA: John Wiley $\&$ Sons.

Schonberger, R. J. (1996). World class manufacturing: The next decade. New York: The Free Press.

Shores, R. A. (1994). Reengineering the factory: A primer for world class manufacturing. Milwaukee, Wisconsin: ASQC Quality Press.

The New Webster Encyclopedic Dictionary of the English Language. (1997). NY: Random House Value Publishing. 